\title{
Clinical and genetic heterogeneity in a large cohort of Armenian patients with late-onset familial Mediterranean fever
}

\author{
Gernot Kriegshäuser, $\mathrm{MD}, \mathrm{PhD}^{1,2 \dagger}$, Dietmar Enko, $\mathrm{MD}^{1,2, \dagger}$, Hasmik Hayrapetyan, $\mathrm{PhD}^{3,4}$, \\ Stepan Atoyan, MD, $\mathrm{PhD}^{3,4}$, Christian Oberkanins, $\mathrm{PhD}^{5}$ and Tamara Sarkisian, MD, PhD ${ }^{3,4}$
}

Purpose: This work aimed at investigating demographic, clinical, and genetic characteristics of individuals experiencing their first familial Mediterranean fever (FMF) attack at age $\geq 40$ years in a very large cohort of Armenian FMF patients.

Methods: In total, 10,370 Armenian patients diagnosed with FMF based on the Tel Hashomer criteria and carrying at least one $M E F V$ mutant allele were included in this study.

Results: A total of 354 (3.40\%) patients had late-onset FMF. Of these, 194 (54.80\%) were female and $160(45.20 \%)$ were male. The following genotypes were significantly associated with the late-onset variant: M680I/E148Q $(P=0.004), \mathrm{M} 694 \mathrm{~V} / \mathrm{E} 148 \mathrm{Q}(P<0.001)$, and V726A/V726A $(P<0.001)$. Of note, $12 / 354(3.40 \%)$ patients were found to be homozygous for the M694V mutation. Individuals with late-onset FMF had a milder disease phenotype presenting significantly less frequent fever, skin manifestation, and chest pain compared to individuals with a disease onset before 40 years of age. Abdominal pain was found more often in the late-onset FMF group, whereas arthritis, proteinuria, and amyloidosis did not differ significantly between the two groups.

Conclusion: Our data suggest that late-onset FMF is more prevalent in women and is of greater clinical as well as genetic heterogeneity than previously reported.

Genet Med advance online publication 15 March 2018

Key Words: disease phenotype; familial Mediterranean fever; late onset; MEFV mutation

\section{INTRODUCTION}

Familial Mediterranean fever (FMF) is an autosomal recessive inherited autoinflammatory disorder that is characterized by recurrent febrile episodes, accompanied by pain in the abdomen (peritonitis), chest (pleuritis), or joints (arthritis), and erysipelas-like skin erythema. ${ }^{1}$ The disease is observed primarily in Armenians, Turks, Arabs, and North African Jews. ${ }^{2}$

FMF is caused by several mutations within the Mediterranean fever $(M E F V)$ gene, which is localized on chromosome 16p13.3. This gene is composed of 10 exons, which encode a 781 -amino acid protein known as pyrin. ${ }^{3,4}$ Four (M694V, M694I, M680I, V726A) and one (E148Q) missense mutations in exon 10 and exon 2, respectively, are the most frequently reported MEVF variants in ethnic groups at risk of FMF. ${ }^{3,5,6}$ With an estimated $20 \%$, the overall $M E F V$ carrier rate in the Armenian population is extremely high, resulting in an FMF prevalence of approximately $3 \%{ }^{7,8}$

In general, FMF diagnosis is based on clinical findings, which can be backed up but never replaced by genetic testing. ${ }^{9}$ Moreover, diagnosing FMF may be extremely difficult in individuals with nonspecific symptoms, with late-onset disease, or with an absence of family history. In such cases, mutational analysis is crucial to enable an early diagnosis. ${ }^{10,11}$

The age of onset of FMF varies with about 60 and 90\% of patients experiencing their first attack before the age of 10 and 20 years, respectively. ${ }^{12}$ Hence, FMF with the first attack occurring at the age of $\geq 40$ years is rare and only a few small studies have investigated the clinical and molecular genetic characteristics of FMF patients with late-onset disease. $^{12-15}$

Therefore, the present study was conducted to better define the subset of late-onset disease in 10,370 Armenian FMF patients by matching $M E F V$ mutational spectra and resulting genotypes against the clinicodemographic profiles collected for these patients between 2005 and 2016.

\section{Ethical approval}

\section{MATERIALS AND METHODS}

The study was approved by the local ethics committee of the Yerevan State Medical University, Yerevan, Armenia, and is in accordance with the latest version of the Declaration of Helsinki. All patients provided written informed consent.

\footnotetext{
${ }^{1}$ Institute of Clinical Chemistry and Laboratory Medicine, General Hospital Steyr, Steyr, Austria; ${ }^{2}$ Clinical Institute of Medical and Laboratory Diagnostics, Medical University of Graz, Graz, Austria; ${ }^{3}$ Center of Medical Genetics and Primary Health Care, Yerevan, Armenia; ${ }^{4}$ Department of Medical Genetics, Yerevan State Medical University, Yerevan, Armenia; ${ }^{5}$ ViennaLab Diagnostics, Vienna, Austria. Correspondence: Gernot Kriegshäuser (gernot.kriegshaeuser@gespag.at)

${ }^{\dagger}$ The first two authors contributed equally to this work.

Submitted 11 August 2017; accepted 9 February 2018; advance online publication 15 March 2018. doi:10.1038/gim.2018.46
} 


\section{FMF patients}

A cohort of 10,370 Armenian patients diagnosed with FMF based on the Tel Hashomer criteria and carrying at least one $M E F V$ mutant allele who visited the Center of Medical Genetics and Primary Health Care in Yerevan between 2005 and 2016 were included in this study. Personal and medical data, including age, sex, age of disease onset, fever, abdominal pain (peritonitis), chest pain (pleuritis), arthritis, skin involvement (erysipelas-like erythema), proteinuria, and amyloidosis were recorded. Disease severity was determined by the use of a scoring system suggested by Pras et al. ${ }^{16}$ Patients also suffering from non-FMF-related inflammation or chronic disease were excluded from the study.

\section{MEFV mutational analysis}

DNA was isolated from anticoagulated blood using the GenXtract DNA extraction system (ViennaLab Diagnostics, Vienna, Austria). Twelve common $M E F V$ mutations including E148Q (c.442G > C) in exon 2; P369S (c.1105C > T) in exon 3; F479L (c.1437C $>$ G) in exon 5; and M680I G/C (c.2040G > C), M680I G/A (c.2040G > A), I692del (c.2076_2078del), M694V (c.2080A > G), M694I (c.2082G> A), K695R (c.2084A > G), V726A (c.2177T >C), A744S (c.2230G $>$ T), and R761H (c.2282G $>A$; RefSeq NG_007871.1) in exon 10 were simultaneously analyzed using a test strip-based reverse-hybridization assay (FMF StripAssay, ViennaLab Diagnostics). The operators were blinded to the patient's disease status.

\section{Statistical analysis}

For subgroup comparison of categorical variables, the chisquare test $(n \times k$ table $)$ and the Fisher's exact test $(2 \times 2$ tables) were calculated. For subgroup comparison of continuous variables in the case of normal distribution (verified by the Kolmogorov-Smirnov test with Lilliefors significance correction) and variance homogeneity (verified by the Levene test) the two-sample independent Student's $t$-test was used. In the case of variance heterogeneity Welch's test was used. In the case of nonnormality the exact Mann-Whitney U test was calculated. All statistical tests were used in an explorative way. Therefore no correction of the type I error (two-sided, 5\%) was made. For all calculations the open-source statistical program package $\mathrm{R}$ version 3.2.3. (R Foundation for Statistical Computing, Vienna, Austria) was used.

\section{Baseline characteristics}

\section{RESULTS}

In total, 10,370 individuals with a clinical diagnosis of FMF were included, of whom 4,881 were female (47.10\%), and $5,489(52.90 \%)$ were male. The mean age was $27.91 \pm 15.98$ years. Of all participants, 3,520 (33.90\%) could be identified with a family history of FMF. Concerning the age of disease onset, 10,016 (96.60\%) and $354(3.40 \%)$ patients experienced their first attack before the age of 40 years and at or after the age of 40 years (i.e., late-onset FMF), respectively.

\section{MEFV mutational spectrum and genotypes}

As listed in Table 1, 59 different genotypes could be distinguished, comprising 2,627 (25.33\%) heterozygous, $6,042(58.26 \%)$ compound heterozygous, and 1,685 (16.25\%) homozygous mutations. Sixteen (0.16\%) individuals had a complex genotype incorporating three mutations. In about $90 \%$ of our cohort, four mutations were most prevalent: M694V (41.34\%), V726A (27.62\%), M680I (18.18\%), and

Table 1 Genotype distribution found in 10,370 familial Mediterranean fever patients

\begin{tabular}{|c|c|c|c|}
\hline \multirow[t]{2}{*}{ Mutation $(n, \%)$} & \multirow[t]{2}{*}{ Genotype } & \multicolumn{2}{|c|}{ Patients } \\
\hline & & $n$ & $\%$ \\
\hline \multirow{11}{*}{$\begin{array}{l}\text { Heterozygous ( } n=2,627 \text {, } \\
25.33 \% \text { ) }\end{array}$} & M694V/- & 1,247 & 12.02 \\
\hline & V726AV- & 567 & 5.47 \\
\hline & E148Q/- & 310 & 2.99 \\
\hline & M680I/- & 297 & 2.86 \\
\hline & R761H/- & 68 & 0.65 \\
\hline & F479L/- & 53 & 0.51 \\
\hline & P369S/- & 35 & 0.34 \\
\hline & A744S/- & 30 & 0.29 \\
\hline & K695R/- & 12 & 0.12 \\
\hline & M694I/- & 8 & 0.08 \\
\hline & Subtotal & 2,627 & 25.33 \\
\hline \multirow{28}{*}{$\begin{array}{l}\text { Compound heterozygous } \\
(n=6,042,58.26 \%)\end{array}$} & M694VN726A & 2,097 & 20.22 \\
\hline & V726A/M680I & 1,215 & 11.72 \\
\hline & M694V/M680I & 1,057 & 10.19 \\
\hline & M694V/E148Q & 388 & 3.74 \\
\hline & V726A/F479L & 336 & 3.24 \\
\hline & M694V/R761H & 275 & 2.65 \\
\hline & M680I/R761H & 150 & 1.45 \\
\hline & V726A/R761H & 99 & 0.95 \\
\hline & M680I/E148Q & 92 & 0.89 \\
\hline & V726A/E148Q & 77 & 0.74 \\
\hline & E148Q/P369S & 48 & 0.46 \\
\hline & M694V/F479L & 44 & 0.42 \\
\hline & M694V/M694I & 27 & 0.26 \\
\hline & M694V/A744S & 25 & 0.24 \\
\hline & V726A/M694I & 23 & 0.22 \\
\hline & M680I/F479L & 17 & 0.16 \\
\hline & M680I/M694I & 16 & 0.15 \\
\hline & E148Q/R761H & 12 & 0.12 \\
\hline & M694V/K695R & 11 & 0.11 \\
\hline & M680I/A744S & 6 & 0.06 \\
\hline & V726A/P369S & 5 & 0.05 \\
\hline & E148Q/M694I & 5 & 0.05 \\
\hline & M694V/P369S & 3 & 0.03 \\
\hline & V726A/A744S & 2 & 0.02 \\
\hline & F479L/E148Q & 2 & 0.02 \\
\hline & M680I/P369S & 2 & 0.02 \\
\hline & E148Q/A744S & 2 & 0.02 \\
\hline & F479L/P369S & 2 & 0.02 \\
\hline
\end{tabular}


Table 1 Continued

\begin{tabular}{|c|c|c|c|}
\hline \multirow[t]{2}{*}{ Mutation $(n, \%)$} & \multirow[t]{2}{*}{ Genotype } & \multicolumn{2}{|c|}{ Patients } \\
\hline & & $n$ & $\%$ \\
\hline & $\mathrm{E} 148 \mathrm{Q} / \mathrm{K} 695 \mathrm{R}$ & 1 & 0.01 \\
\hline & M680I/K695R & 1 & 0.01 \\
\hline & $\mathrm{R} 761 \mathrm{H} / \mathrm{K} 695 \mathrm{R}$ & 1 & 0.01 \\
\hline & F479L/R761H & 1 & 0.01 \\
\hline & Subtotal & 6,042 & 58.26 \\
\hline \multirow{8}{*}{$\begin{array}{l}\text { Homozygous ( } n=1,685 \\
16.25 \% \text { ) }\end{array}$} & M694V/M694V & 1,153 & 11.12 \\
\hline & V726AN726A & 288 & 2.77 \\
\hline & M680I/M680I & 220 & 2.12 \\
\hline & E148Q/E148Q & 8 & 0.08 \\
\hline & $\mathrm{R} 761 \mathrm{H} / \mathrm{R} 761 \mathrm{H}$ & 8 & 0.08 \\
\hline & F479L/F479L & 7 & 0.07 \\
\hline & A744S/A744S & 1 & 0.01 \\
\hline & Subtotal & 1,685 & 16.25 \\
\hline \multirow[t]{21}{*}{ Complex $(n=16,0.16 \%)$} & M694V/M694V/ & 4 & 0.04 \\
\hline & E148Q & & \\
\hline & M694VN726AV & 2 & 0.02 \\
\hline & E148Q & & \\
\hline & V726AN726A & 2 & 0.02 \\
\hline & E148Q & & \\
\hline & V726A/M680I/ & 2 & 0.02 \\
\hline & E148Q & & \\
\hline & M694VN726AV & 1 & 0.01 \\
\hline & M680I & & \\
\hline & M694V/E148Q/ & 1 & 0.01 \\
\hline & P369S & & \\
\hline & V726A/F479L & 1 & 0.01 \\
\hline & E148Q & & \\
\hline & M694V/M694V/ & 1 & 0.01 \\
\hline & P369S & & \\
\hline & E148Q/E148Q/ & 1 & 0.01 \\
\hline & P369S & & \\
\hline & V726A/E148Q/ & 1 & 0.01 \\
\hline & $\mathrm{R} 761 \mathrm{H}$ & & \\
\hline & Subtotal & 16 & 0.16 \\
\hline Total & & 10,370 & 100.00 \\
\hline
\end{tabular}

E148Q (5.34\%). Six other mutations (R761H, F479L, P369S, A744S, M694I, and K695R) were found with a distinctly lower frequency (Table 2).

The mutational spectrum obtained for 10,016 (96.60\%) and 354 (3.40\%) FMF patients with an age of onset $<40$ and $\geq 40$ years is illustrated in Table 3. Genotypes M680I/E148Q $(P=0.004), \mathrm{M} 694 \mathrm{~V} / \mathrm{E} 148 \mathrm{Q}(P<0.001)$, and V726A/V726A $(P<0.001)$ were significantly associated with the late-onset variant whereas genotypes $\mathrm{M} 694 \mathrm{~V} / \mathrm{M} 694 \mathrm{~V} \quad(P<0.001)$, V726A/F479L $(P=0.005)$, and V726A/M680I $(P=0.023)$ were more frequently observed in patients with a disease onset $<40$ years. Of note, 12/354 (3.39\%) patients with lateonset FMF were found to be homozygous for the M694V mutation.
Table 2 MEFV allele frequencies found in 10,370 familial Mediterranean fever patients

\begin{tabular}{lll} 
Allele & Number of alleles & Frequency (\%) \\
\hline M694V & 7,494 & 41.34 \\
\hline V726A & 5,008 & 27.62 \\
\hline M680I & 3,296 & 18.18 \\
\hline E148Q & 968 & 5.34 \\
\hline R761H & 623 & 3.44 \\
\hline F479L & 470 & 2.59 \\
\hline P369S & 98 & 0.54 \\
\hline M694I & 79 & 0.44 \\
\hline A744S & 67 & 0.37 \\
\hline K695R & 26 & 0.14 \\
\hline Total & 18,129 & 100.00 \\
\hline
\end{tabular}

\section{Clinical aspects of the late-onset disease}

The demographic aspects and clinical manifestations of FMF patients with age of onset $<40$ and $\geq 40$ years are presented in Table 4. In the late-onset FMF group $(n=354)$ the mean age (female, 194 (54.80\%); male, 160 (45.20\%)) was $56.97 \pm 7.82$ years. For those patients with a disease onset before 40 years of age the mean age at onset of disease was $11.86 \pm 9.66$ years.

The frequencies of FMF-related clinical manifestations were significantly different between the two groups except for arthritis, proteinuria, and amyloidosis. Patients with disease onset $\geq 40$ years of age showed a milder disease phenotype $(P<0.001)$ presenting significantly less frequent fever $(89.55$ vs. $92.46 \%, P=0.048$ ), skin manifestation (9.89 vs. $14.99 \%$, $P=0.009)$, and chest pain (43.22 vs. $48.66 \%, P=0.046)$ compared to individuals with a disease onset before 40 years of age. However, abdominal pain was significantly more frequent in patients with late-onset disease ( 90.40 vs. $86.42 \%$, $P=0.035)$.

\section{DISCUSSION}

In this study, $M E F V$ mutational spectra and resulting genotypes were matched against the clinicodemographic profiles of 10,370 FMF patients including 354 (3.40\%) individuals with late-onset disease. The most frequently observed mutations were M694V (41.34\%), V726A (27.62\%), and M680I (18.18\%), whereas all other mutations were found with distinctly lower frequencies. These findings are in line with two earlier Armenian studies that observed M694V (50.60 and 56.10\%), V726A (22.30 and 17.90\%), and M680I (18.70 and $17.90 \%)$ to be most common including 3,000 and 1,299 FMF patients, respectively. ${ }^{7,17}$

With respect to the genotype distribution among FMF patients, we found the following genotypes to be most frequent: M694V/V726A (20.22\%), M694V/- (12.02\%), M680I/V726A (11.72\%), M694V/M694V (11.12\%), M694V/ M680I (10.19\%), V726A/- (5.47\%), and M694V/E148Q (3.74\%). In contrast, a previous Armenian study comprising 3,000 FMF patients found a divergent order: M694V/M694V (20.90\%), M694V/V726A (18.00\%), M694V/M680I (12.70\%), 
Table 3 Mutation frequencies found in familial Mediterranean fever patients according to age of onset

\begin{tabular}{|c|c|c|c|c|c|c|}
\hline & \multirow[t]{2}{*}{ Total } & \multicolumn{2}{|c|}{$<40$ years } & \multicolumn{2}{|c|}{$\geq \mathbf{4 0}$ years } & \multirow[t]{2}{*}{$P$ value } \\
\hline & & $n$ & $\%$ & $n$ & $\%$ & \\
\hline A744S/- & 30 & 27 & 0.27 & 3 & 0.85 & 0.081 \\
\hline A744S/A744S & 1 & 1 & 0.01 & 0 & 0.00 & - \\
\hline E148Q/- & 310 & 301 & 3.01 & 9 & 2.54 & 0.751 \\
\hline E148Q/A744S & 2 & 2 & 0.02 & 0 & 0.00 & - \\
\hline E148Q/E148Q & 8 & 7 & 0.07 & 1 & 0.28 & 0.243 \\
\hline E148Q/M694I & 5 & 4 & 0.04 & 1 & 0.28 & 0.159 \\
\hline E148Q/E148Q/P369S & 1 & 1 & 0.01 & 0 & 0.00 & - \\
\hline E148Q/K695R & 1 & 1 & 0.01 & 0 & 0.00 & - \\
\hline E148Q/P369S & 48 & 48 & 0.48 & 0 & 0.00 & - \\
\hline $\mathrm{E} 148 \mathrm{Q} / \mathrm{R} 761 \mathrm{H}$ & 12 & 11 & 0.11 & 1 & 0.28 & 0.341 \\
\hline F479L- & 53 & 51 & 0.51 & 2 & 0.56 & 0.703 \\
\hline F479L/E148Q & 2 & 2 & 0.02 & 0 & 0.00 & - \\
\hline F479L/F479L & 7 & 7 & 0.07 & 0 & 0.00 & - \\
\hline F479L/P369S & 2 & 2 & 0.02 & 0 & 0.00 & - \\
\hline F479L/R761H & 1 & 1 & 0.01 & 0 & 0.00 & - \\
\hline K695R/- & 12 & 12 & 0.12 & 0 & 0.00 & - \\
\hline M680I/- & 297 & 283 & 2.83 & 14 & 3.95 & 0.195 \\
\hline M680I/A744S & 6 & 6 & 0.06 & 0 & 0.00 & - \\
\hline M680I/E148Q & 92 & 83 & 0.83 & 9 & 2.54 & 0.004 \\
\hline M680I/F479L & 17 & 15 & 0.15 & 2 & 0.56 & 0.113 \\
\hline M680I/K695R & 1 & 1 & 0.01 & 0 & 0.00 & - \\
\hline M680I/M680I & 220 & 214 & 2.14 & 6 & 1.69 & 0.708 \\
\hline M680I/M694I & 16 & 15 & 0.15 & 1 & 0.28 & 0.427 \\
\hline M680I/P369S & 2 & 2 & 0.02 & 0 & 0.00 & - \\
\hline M680I/R761H & 150 & 143 & 1.43 & 7 & 1.98 & 0.361 \\
\hline M694I/- & 8 & 7 & 0.07 & 1 & 0.28 & 0.243 \\
\hline M694V/- & 1,247 & 1,197 & 11.95 & 50 & 14.12 & 0.212 \\
\hline M694V/A744S & 25 & 24 & 0.24 & 1 & 0.28 & 0.581 \\
\hline M694V/E148Q & 388 & 361 & 3.60 & 27 & 7.63 & $<0.001$ \\
\hline $\begin{array}{l}\text { M694V/E148Q/ } \\
\text { P369S }\end{array}$ & 1 & 1 & 0.01 & 0 & 0.00 & - \\
\hline M694V/F479L & 44 & 42 & 0.42 & 2 & 0.56 & 0.662 \\
\hline M694V/K695R & 11 & 10 & 0.10 & 1 & 0.28 & 0.318 \\
\hline M694V/M680I & 1,057 & 1,028 & 10.26 & 29 & 8.19 & 0.244 \\
\hline M694V/M694I & 27 & 26 & 0.26 & 1 & 0.28 & 0.609 \\
\hline M694V/M694V & 1,153 & 1,141 & 11.39 & 12 & 3.39 & $<0.001$ \\
\hline $\begin{array}{l}\text { M694V/M694V/ } \\
\text { E148Q }\end{array}$ & 4 & 4 & 0.04 & 0 & 0.00 & - \\
\hline $\begin{array}{l}\text { M694V/M694V/ } \\
\text { P369S }\end{array}$ & 1 & 1 & 0.01 & 0 & 0.00 & - \\
\hline M694V/P369S & 3 & 3 & 0.03 & 0 & 0.00 & - \\
\hline M694V/R761H & 275 & 264 & 2.64 & 11 & 3.11 & 0.611 \\
\hline M694VN726A & 2,097 & 2,013 & 20.10 & 84 & 23.73 & 0.106 \\
\hline $\begin{array}{l}\text { M694VN726A } \\
\text { E148Q }\end{array}$ & 2 & 2 & 0.02 & 0 & 0.00 & - \\
\hline $\begin{array}{l}\text { M694VN726A } \\
\text { M680I }\end{array}$ & 1 & 1 & 0.01 & 0 & 0.00 & - \\
\hline P369S/- & 35 & 32 & 0.32 & 3 & 0.85 & 0.116 \\
\hline R761H/- & 68 & 66 & 0.66 & 2 & 0.56 & $>0.999$ \\
\hline R761H/K695R & 1 & 1 & 0.01 & 0 & 0.00 & - \\
\hline $\mathrm{R} 761 \mathrm{H} / \mathrm{R} 761 \mathrm{H}$ & 8 & 8 & 0.08 & 0 & 0.00 & - \\
\hline
\end{tabular}

Table 3 Continued

\begin{tabular}{|c|c|c|c|c|c|c|}
\hline & \multirow[t]{2}{*}{ Total } & \multicolumn{2}{|c|}{$<\mathbf{4 0}$ years } & \multicolumn{2}{|c|}{$\geq \mathbf{4 0}$ years } & \multirow[t]{2}{*}{$P$ value } \\
\hline & & $n$ & $\%$ & $n$ & $\%$ & \\
\hline V726A/- & 567 & 553 & 5.52 & 14 & 3.95 & 0.234 \\
\hline V726A/A744S & 2 & 2 & 0.02 & 0 & 0.00 & - \\
\hline V726A/E148Q & 77 & 74 & 0.74 & 3 & 0.85 & 0.747 \\
\hline $\begin{array}{l}\text { V726A/E148Q/ } \\
\text { R761H }\end{array}$ & 1 & 1 & 0.01 & 0 & 0.00 & - \\
\hline V726A/F479L & 336 & 333 & 3.32 & 3 & 0.85 & 0.005 \\
\hline V726A/F479L/E148Q & 1 & 1 & 0.01 & 0 & 0.00 & - \\
\hline V726A/M680I & 1,215 & 1,187 & 11.85 & 28 & 7.91 & 0.023 \\
\hline V726A/M680I/E148Q & 2 & 2 & 0.02 & 0 & 0.00 & - \\
\hline V726A/M694I & 23 & 21 & 0.21 & 2 & 0.56 & 0.172 \\
\hline V726A/P369S & 5 & 5 & 0.05 & 0 & 0.00 & - \\
\hline V726A/R761H & 99 & 98 & 0.98 & 1 & 0.28 & 0.266 \\
\hline V726AN726A & 288 & 265 & 2.65 & 23 & 6.50 & $<0.001$ \\
\hline $\begin{array}{l}\text { V726AN726A } \\
\text { E148Q }\end{array}$ & 2 & 2 & 0.02 & 0 & 0.00 & - \\
\hline Total & 10,370 & 10,016 & 100 & 354 & 100 & \\
\hline
\end{tabular}

Table 4 Clinicodemographic profiles of familial Mediterranean fever patients with age of onset $<40$ and $\geq 40$ years

\begin{tabular}{lccc} 
& \multicolumn{4}{c}{$\mathbf{4 0}$ years } & $\mathbf{4} \mathbf{4 0}$ years & $P$ value \\
\hline & $n=\mathbf{1 0 , 0 1 6}$ & $n=\mathbf{3 5 4}$ & \\
\hline Mean age, years & $26.89 \pm 15.20$ & $56.97 \pm 7.82$ & $<0.001$ \\
\hline Mean age of onset, years & $11.86 \pm 9.66$ & $46.02 \pm 5.57$ & - \\
\hline Gender & & & \\
\hline Male & $5,329(53.20 \%)$ & $160(45.20 \%)$ & 0.003 \\
\hline Female & $4,687(46.80 \%)$ & $194(54.80 \%)$ & \\
\hline Family history of FMF & $3,414(34.09 \%)$ & $106(29.94 \%)$ & 0.111 \\
\hline Fever $\left(\geq 38{ }^{\circ} \mathrm{C}\right)$ & $9,261(92.46 \%)$ & $317(89.55 \%)$ & 0.048 \\
\hline Arthritis & $1,690(16.87 \%)$ & $62(17.51 \%)$ & 0.778 \\
\hline Skin rash (erysipelas-like & $1,501(14.99 \%)$ & $35(9.89 \%)$ & 0.009 \\
erythema) & & & \\
\hline Abdominal pain & $8,656(86.42 \%)$ & $320(90.40 \%)$ & 0.035 \\
\hline Chest pain & $4,874(48.66 \%)$ & $153(43.22 \%)$ & 0.046 \\
\hline Proteinuria & $142(1.42 \%)$ & $7(1.98 \%)$ & 0.359 \\
\hline Amyloidosis & $61(0.61 \%)$ & $2(0.56 \%)$ & $>0.999$ \\
\hline Pras & & & \\
\hline Mild & $4,579(45.72 \%)$ & $238(67.23 \%)$ & $<0.001$ \\
\hline Moderate & $4,936(49.28 \%)$ & $115(32.49 \%)$ & \\
\hline Severe & $501(5.00 \%)$ & $1(0.28 \%)$ & \\
\hline
\end{tabular}

FMF, familial Mediterranean fever.

M680I/V726A (9.80\%), M680I/M680I (3.40\%), V726A/ V726A (2.80\%), and M694V/R761H (2.80\%). Additionally, we identified a lower rate of FMF patients with complex alleles $(0.16 \text { vs. } 0.70 \%)^{7}$

Here, we found 354 (3.40\%) of 10,370 patients who experienced their first FMF attack at an age of $\geq 40$ years and were more often of female gender (female, 194 (54.80\%); male, $160(45.20 \%))$. An earlier study on late-onset FMF in 
Israel has reported different results indicating a lower rate of late-onset disease $(20 / 4,000$ individuals (0.5\%)) and a predominant male gender among late-onset FMF patients (female, 4 (20\%); male, $16(80 \%)) .{ }^{12}$ Moreover, we observed different frequencies for the following genotypes: M694V/ M694V (12/354 (3.39\%) vs. 0/14 (0.00\%)), M694V/V726A $(84 / 354(23.73 \%)$ vs. $2 / 14$ (14.0\%), V726A/V726A (23/354 (6.50\%) vs. $3 / 14(21.40 \%))$, V726A/E148Q (3/354 (0.85\%) vs. 0/14 (0.00\%), and E148Q/E148Q (1/354 (0.28\%) vs. 0/14 $(0.00 \%))$. While amyloidosis has been described in patients with a disease onset after age $40,{ }^{15}$ this is, to the best of our knowledge, the first report on M694V homozygosity in lateonset FMF patients. This finding is of special interest because several studies have associated M694V homozygosity with an earlier age of onset and a more severe disease phenotype. ${ }^{17-23}$ Corroborating previous data, ${ }^{12}$ none of our late-onset FMF patients carried the complex allele V726A-E148Q, which is known to be present in individuals with a severe disease phenotype. 22,23

In the current study, genotypes M680I/E148Q $(P=0.004)$, M694V/E148Q $(P<0.001)$, and V726A/V726A $(P<0.001)$ were significantly associated with the late-onset variant. While genotypes M694V/E148Q and V726A/V726A have already been described in FMF patients with late-onset and/or milder disease, ${ }^{12,23}$ this is the first report to correlate genotype M680I/ E148Q with the late-onset variant, supporting the observation that both mutations M680I and E148Q associate with a less severe disease activity. ${ }^{7,12,23}$ Furthermore, mutation E148Q has been shown to predispose to a prolonged disease onset. ${ }^{17}$

Small study populations comprising small percentages of late-onset patients only are the major limitations of studies published so far. ${ }^{12-15}$ For example, based on their findings in 20 late-onset FMF patients Tamir et al. ${ }^{12}$ suggested a milder disease course without proteinuria and amyloidosis presenting significantly less arthritis, chest pain, fever, and skin manifestations and a nonsignificant difference in abdominal pain compared to patients with an age of onset before 40 years of age.

The results of this study support the concept of late-onset FMF as being a less symptomatic disease variant. Patients with an age of onset before 40 years had significantly more frequent fever $(P=0.048)$, skin involvement $(P=0.009)$, chest pain $(P=0.046)$, and a more severe disease phenotype $(P<0.001)$ compared to the group of patients with an age of onset $\geq 40$ years. Interestingly, abdominal pain was found more often in the late-onset FMF group $(P=0.035)$, whereas arthritis, proteinuria, and amyloidosis did not differ significantly between the two groups.

The main strength of this retrospective study is its sample size, which enables the clinical and genetic characterization of 354 patients with late-onset FMF. However, it is limited by the fact that genetic analysis was performed for the 12 most common $M E F V$ mutations only, thus neglecting less frequent ones. Another limitation of this work is the lack of information regarding response and compliance to colchicine treatment.
Our data suggest that late-onset FMF is more prevalent in women and is of greater clinical as well as genetic heterogeneity than previously reported. Therefore physicians should include FMF in their differential diagnosis list even when evaluating older patients with a relevant ethnic background. Moreover, further studies including late-onset FMF patients homozygous for $M E F V$ mutation M694V may lead to the identification of novel disease-modifying mechanisms.

\section{DISCLOSURE}

The authors declare no conflict of interest

\section{REFERENCES}

1. Portincasa P, Scaccianoce $G$ \& Palasciano G. Familial Mediterranean fever: a fascinating model of inherited autoinflammatory disorder. Eur J Clin Invest 2013;43:1314-1327.

2. Shohat M \& Halpern GJ. Familial Mediterranean fever-a review. Genet Med 2011;13:487-498.

3. Touitou I. The spectrum of familial Mediterranean fever (FMF) mutations. Eur J Hum Genet 2001;9:473-483.

4. Fujikura K. Global epidemiology of familial Mediterranean fever mutations using population exome sequences. Mol Genet Genomic Med 2015;3: 272-282.

5. Gershoni-Baruch R, Shinawi M, Leah K, et al. Familial Mediterranean fever: prevalence, penetrance and genetic drift. Eur J Hum Genet 2001;9: 634-637.

6. Dodé C, Pêcheux C, Cazeneuve C, et al. Mutations in the MEFV gene in a large series of patients with a clinical diagnosis of familial Mediterranean fever. Am J Med Genet 2000;92:241-246.

7. Sarkisian T, Ajrapetyan H \& Shahsuvaryan G. Molecular study of FMF patients in Armenia. Curr Drug Targets Inflamm Allergy 2005;4:113-116.

8. Moradian MM, Sarkisian T, Amaryan G, et al. Patient management and the association of less common familial Mediterranean fever symptoms with other disorders. Genet Med 2014;16:258-263.

9. Giancane G, Ter Haar NM, Wulffraat N, et al. Evidence-based recommendations for genetic diagnosis of familial Mediterranean fever. Ann Rheum Dis 2015;74:635-641.

10. Grateau G, Pêcheux C, Cazeneuve C, et al. Clinical versus genetic diagnosis of familial Mediterranean fever. QJM 2000;93:223-229.

11. Oberkanins C, Weinhäusel A, Kriegshäuser G, et al. Genetic testing for familial Mediterranean fever in Austria by means of reverse-hybridization teststrips. Clin Chem 2003;49:1948-1950.

12. Tamir N, Langevitz $P$, Zemer $D$, et al. Late-onset familial Mediterranean fever (FMF): a subset with distinct clinical, demographic, and molecular genetic characteristics. Am J Med Genet 1999;87:30-35.

13. Sayarlioglu M, Cefle $A$, Inanc $M$, et al. Characteristics of patients with adult-onset familial Mediterranean fever in Turkey: analysis of 401 cases. Int J Clin Pract 2005;59:202-205.

14. Nobakht $H$, Zamani $F$, Ajdarkosh $H$, et al. Adult-onset familial Mediterranean fever in Northwestern Iran; clinical feature and treatment outcome. Middle East J Dig Dis 2011;3:50-55.

15. Tunca M, Akar S, Onen F, et al. Familial Mediterranean fever (FMF) in Turkey: results of a nationwide multicenter study. Medicine (Baltimore) 2005;84:1-11.

16. Pras $E$, Livneh $A$, Balow Jr JE, et al. Clinical differences between North African and Iraqi Jews with familial Mediterranean fever. Am J Med Genet 1998;13:216-219.

17. Moradian MM, Sarkisian T, Ajrapetyan H, et al. Genotype-phenotype studies in a large cohort of Armenian patients with familial Mediterranean fever suggest clinical disease with heterozygous MEFV mutations. J Hum Genet 2010;55:389-393.

18. Dewalle $M$, Domingo $C$, Rozenbaum $M$, et al. Phenotype-genotype correlation in Jewish patients suffering from familial Mediterranean fever (FMF). Eur J Hum Genet 1998;6:95-97.

19. Cazeneuve C, Sarkisian T, Pecheux C, et al. MEFV-gene analysis in Armenian patients with familial Mediterranean fever: diagnostic value and unfavorable renal prognosis of the M694V homozygous genotypegenetic and therapeutic implications. Am J Hum Genet 1999;65:88-97. 
20. Ben-Chetrit E \& Backenroth R. Amyloidosis induced, end stage renal disease in patients with familial Mediterranean fever is highly associated with point mutations in the MEFV gene. Ann Rheum Dis. 2001;60: 146-149.

21. Lidar $\mathrm{M}$, Yonath $\mathrm{H}$, Shechter $\mathrm{N}$, et al. Incomplete response to colchicine in M694V homozygote FMF patients. Autoimmun Rev 2012;12:72-76.
22. Livneh $\mathrm{A}$, Langevitz $\mathrm{P}$, Shinar $\mathrm{Y}$, et al. MEFV mutation analysis in patients suffering from amyloidosis of familial Mediterranean fever. Amyloid Int J Exp Clin Invest 1999:6:1-6.

23. Gershoni-Baruch R, Brik R, Shinawi M, et al. The differential contribution of MEFV mutant alleles to the clinical profile of familial Mediterranean fever. Eur J Hum Genet 2002;10:145-149. 